\title{
Incidence and Knowledge of Diabetes Mellitus of the Residents of Tura Town: A Case Study
}

\author{
Natasha Marak*, D. Alina, Ch. Momin and G. Leebeliya Sharma \\ Department of Food Science \& Nutrition, College of Home Science, Central Agricultural \\ University, Tura, Meghalaya-794005, India \\ *Corresponding author
}

\section{A B S T R A C T}

\begin{tabular}{|l|}
\hline K e y w o r d s \\
$\begin{array}{l}\text { Diabetes mellitus, } \\
\text { Incidence, } \\
\text { Knowledge, Rural, } \\
\text { Urban, Lifestyle }\end{array}$ \\
\hline Article Info \\
\hline $\begin{array}{l}\text { Accepted: } \\
\text { 12 August } 2018 \\
\text { Available Online: } \\
\text { 10 September } 2018\end{array}$ \\
\hline
\end{tabular}

Diabetes is a huge problem in India and continues to be the 'diabetes capital' in the world. Hence, a cross-sectional study was carried out to evaluate the incidence of Diabetes Mellitus among the outpatients in the Tura Civil Hospital located in a small town in the North-eastern State of Meghalaya, India. A total of 100 outpatients were randomly selected and data were collected by interview method using a pre-designed and prestructured questionnaire. The results showed that the prevalence of Diabetes was very high, with the incidence of Diabetes higher in the age group of fifty to sixty years (44\%), with more males (64\%) suffering from Diabetes than females (36\%). In comparison to the rural area, the urban area had a higher percentage (55\%) suffering from Diabetes. Nonvegetarians $(88 \%)$ and patients who lived a sedentary lifestyle $(73 \%)$ were mostly associated with the disease. The knowledge of the patients about the disease was also found to be very poor. Hence, preventive measures and awareness regarding Diabetes Mellitus to serve the population and halt and reduce the prevalence of Diabetes Mellitus are necessary

\section{Introduction}

Diabetes is a chronic disease causing significant mortality and morbidity worldwide and hence, is an important public health problem, one of the four priority noncommunicable diseases (NCDs) targeted for action by the world leaders. Both the number of cases and the prevalence of diabetes have been gradually increasing over the past few decades (WHO, 2016).

Diabetes is a huge problem in India and continues to be the 'diabetes capital' in the world. According to a study conducted by the International Diabetes Federation, nearly $9 \%$ of India's population is likely to be affected with diabetes by 2030 (Hindustan Times, 2017).

According to the International Journal of Diabetes in Developing Countries, India has been witnessing an alarming rise in the incidence of diabetes and an estimated 3.4 million deaths due to high blood sugar have been report by the World Health Organization (WHO) fact sheet on diabetes. The WHO also estimates that 80 per cent of diabetes deaths 
occur in low and middle-income countries and projects that such deaths will double between 2016 and 2030. It has also been estimated that the global incidence of Type II diabetes is expected to increase to 438 million by 2030 (Malik, 2016).

There is very little data on the prevalence rates and awareness about Diabetes Mellitus in a country like India. Hence this study was taken up to identify the prevalence rates and evaluate the knowledge and practices of the people residing in North East Indian State of Meghalaya's small town called Tura with a population of 74,858 (2011 census).

\section{Materials and Methods}

A cross-sectional hospital-based study was conducted at Tura Civil Hospital, Meghalaya in the Out Patient Department (OPD) for Non Communicable Disease (NCD) for a period of 2 months. A pre-designed and pre-structured questionnaire was prepared in English language to analyse the prevalence/incidence of diabetes. The questionnaire consists of patient's profile, knowledge about Diabetes Mellitus, patient's medical history and lifestyle practices and perceptions.

The data was carried out using a face-to-face interview method. Each interview was conducted in the outpatient department. A total number of 100 respondents were randomly selected in the study. The data collected was coded and analysed in the excel sheets using Microsoft Excel 2016.

\section{Results and Discussion}

As evidenced from Table 1, the majority of the patients $(44 \%)$ were in the age group of fifty to sixty years followed by $31 \%$ who were in the age group of forty to fifty which shows that diabetes is more common among the middle aged and elderly. This is in accordance with the book by Srilakshmi (2014) "Dietetics" where it is stated that the incidence of Diabetes Mellitus is more common in the middle aged and elderly. The incidence of diabetes in males $(64 \%)$ was more common than females (36\%). In a similar research conducted by Yang et al., (2010) it was found that the incidence of Diabetes Mellitus was found to be more in males than females. $44 \%$ of the interviewed patients were unemployed with $81 \%$ being literate while $19 \%$ were found to be illiterate. There were $55 \%$ percent of the patients from the urban area and $45 \%$ from the rural area. In a similar research conducted by Aung et al., (2018) it was found that the incidence of diabetes is higher in the urban area than in the rural area. According to the $C A D I$ (Coronary Artery Disease among Asian Indians) Research Foundation, India is facing an outbreak of Diabetes Mellitus; with the incidence of diabetes in urban India being approximately double than that of the rural area. $98 \%$ of the patients were married with $88 \%$ being non-vegetarians. Thus, it can be concluded that non vegetarians are more prone to diabetes than the vegetarians. A study conducted by Tonstad et al., (2013) and several other studies conducted by other researchers have also shown the association of non-vegetarian diet with diabetes and vegetarian diets with a reduction in the incidence of diabetes. In terms of physical activity, the majority of the patients $(73 \%)$ led a sedentary which shows that sedentary lifestyle is a contributing factor for the incidence of diabetes in the study population. A similar study conducted by Joshua J. Joseph, et al., (2016) found that the incidence of Diabetes Mellitus especially that of Type II was inversely associated with physical activity while sedentary behaviours were found to be positively associated. Majority (46\%) of the patients have been suffering from diabetes for less than one year while there are others who have been suffering for more than one year. 
$51 \%$ of the patients had a normal BMI while a total of $41 \%$ were obese and a total of $8 \%$ were below the normal BMI (Fig. 1).

$49 \%$ of the patients had no idea about the causes of diabetes, while $36 \%$ considered that food is the main cause of the disease, 3\% thought that lack of exercise/sedentary lifestyle is the main cause while others were of the belief that tension/stress (7\%) and genetics/heredity $(5 \%)$ can also lead to Diabetes (Fig. 2). The major causes of Diabetes Mellitus however are auto-immune disorders, sedentary lifestyle, acute stress, genetics, age, pregnancy and infections (Srilakshmi, 2014).

Only a total of $11 \%$ patients had a correct knowledge about the cause of Diabetes out of which 5\% were from the rural area and 6\% were from the urban area. The majority (89\%) of the patients either had incorrect knowledge or no knowledge about the cause of Diabetes out of which $40 \%$ were from the rural area and 49\% from the urban area (Table 2). Thus, education and awareness regarding Diabetes Mellitus is needed.

Majority (41\%) thought that frequent thirst is the common symptom of diabetes, while 19\% considered other symptoms like slow healing of wounds, light-headedness, leg and joint pain, headache, painful urination, blurred vision and tingling sensation as the signs or symptoms of diabetes (Fig. 3). 38\% were aware that eye disease is the complication of diabetes while $12 \%$ believed that heart disease is the main complication (Fig. 4). Drugs/medication was believed by the majority (56\%) to help control diabetes while $1 \%$ of the patients felt that other measures like consuming bitter foods and avoiding sweets can control diabetes (Fig. 5). A total of 55\% patients were hypertensive patients while $25 \%$ had normal blood pressure and $20 \%$ had an elevated blood pressure (Fig. 6).
According to Katayama et al., (2018), over $50 \%$ of the patients with Diabetes Mellitus, eventually develop hypertension as a complication which increases the incidence of cardiovascular disease (CVD) by two to three folds and accelerates the progression of diabetic nephropathy.

The majority $(71 \%)$ had no family history of Diabetes (Fig. 7). $72 \%$ of the patients have not been hospitalized for Diabetes, while 28\% have been hospitalized (Fig. 8). While $46 \%$ of the patients include exercise in their routine, 54\% did not exercise (Fig. 9).

Out of the $46 \%$ of patients who indulged in exercise, only $52 \%$ exercised daily while $42 \%$ exercised sometimes (Fig. 10). In a study conducted by Thompson PD, et al., (2003) it was found that daily exercise can improve blood glucose control and reduce the deaths in patients with type II diabetes.

Walking as a form of daily physical activity, was also found to have beneficial effects on reducing the risk of type II Diabetes Mellitus and cardiovascular disease.

A majority of the patients (59\%) exercised for duration of less than one hour, while $41 \%$ exercised for duration of one hour or more. Brisk walking and jogging were the major forms of exercise practiced (Fig. 11).

$76 \%$ of the patients were non-smokers while $24 \%$ indulged in smoking (Fig. 12). Out of the $24 \%$ patients who are smokers, $54 \%$ smoke daily while $46 \%$ smoke sometimes (Fig. 13). Majority (46\%) smoked 1 to 5 cigarettes (Fig. 14).

$87 \%$ of the patients did not consume alcohol while $13 \%$ did (Fig. 15). Out of the $13 \%$ of the patients who consumed alcohol, 77\% consumed alcohol sometimes while 8\% consumed alcohol occasionally (Fig. 16). 
Table.1 Patient profile (N=100)

\begin{tabular}{|c|c|c|}
\hline Patient Profile & Frequency & $\%$ \\
\hline \multicolumn{3}{|l|}{ AGE } \\
\hline $30-40$ & 12 & 12 \\
\hline $40-50$ & 31 & 31 \\
\hline $50-60$ & 44 & 44 \\
\hline 60-70 & 9 & 9 \\
\hline 70-80 & 4 & 4 \\
\hline \multicolumn{3}{|l|}{ GENDER } \\
\hline Male & 64 & 64 \\
\hline Female & 36 & 36 \\
\hline \multicolumn{3}{|l|}{ OCCUPATION } \\
\hline Unemployed & 44 & 44 \\
\hline Self-employed & 16 & 16 \\
\hline Government Service & 22 & 22 \\
\hline Military Service & 18 & 18 \\
\hline \multicolumn{3}{|c|}{ EDUCATIONAL QUALIFICATION } \\
\hline Graduate & 11 & 11 \\
\hline Higher Secondary & 17 & 17 \\
\hline Matric passed & 17 & 17 \\
\hline Under-matric & 36 & 36 \\
\hline Illiterate & 19 & 19 \\
\hline \multicolumn{3}{|c|}{ GEOGRAPHICAL AREA } \\
\hline Rural & 45 & 45 \\
\hline Urban & 55 & 55 \\
\hline \multicolumn{3}{|l|}{ MARITAL STATUS } \\
\hline Married & 98 & 98 \\
\hline Unmarried & 2 & 2 \\
\hline \multicolumn{3}{|l|}{ FOOD PATTERN } \\
\hline Vegetarian & 12 & 12 \\
\hline Non-vegetarian & 88 & 88 \\
\hline \multicolumn{3}{|c|}{ PHYSICAL ACTIVITY } \\
\hline Sedentary worker & 73 & 73 \\
\hline Moderate worker & 27 & 27 \\
\hline Heavy worker & 0 & 0 \\
\hline \multicolumn{3}{|c|}{ DURATION OF DISEASE } \\
\hline$<1$ year & 46 & 46 \\
\hline 1year-5years & 34 & 34 \\
\hline 5years-10years & 11 & 11 \\
\hline 10years-15years & 5 & 5 \\
\hline 15years-20years & 4 & 4 \\
\hline
\end{tabular}


Table. 2 Knowledge about the causes of diabetes according to the geographical area $(\mathrm{N}=100)$

\begin{tabular}{|l|l|l|l|l|} 
& Correct & \multicolumn{2}{l|}{ Incorrect/ No knowledge } \\
\hline Geographical Area & Rural & Urban & Rural & Urban \\
\hline Frequency & 5 & 6 & 40 & 49 \\
\hline Percentage & 5 & 6 & 40 & 49
\end{tabular}

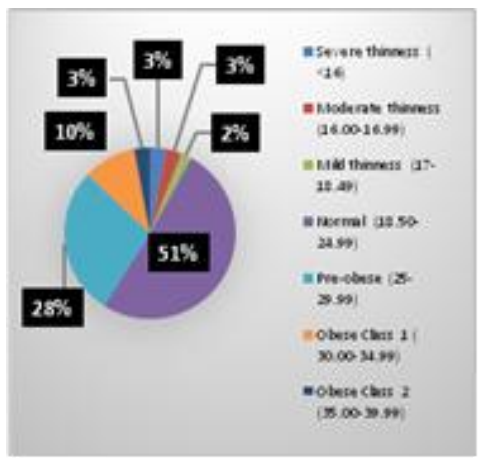

Figure 1: BMll of the potie ntt

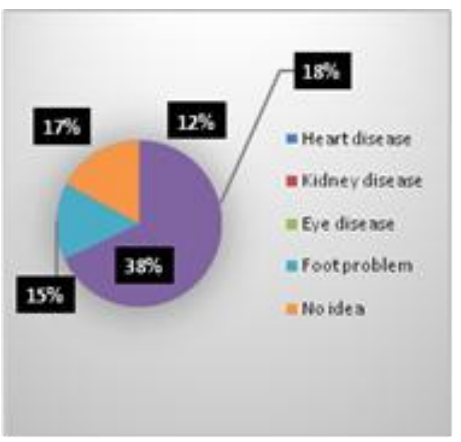

Figure 5: Knowledge about the complications of Diabetes

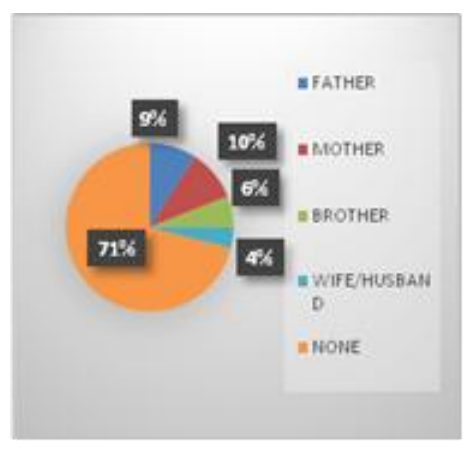

Figure 6: Family history of Diabetes

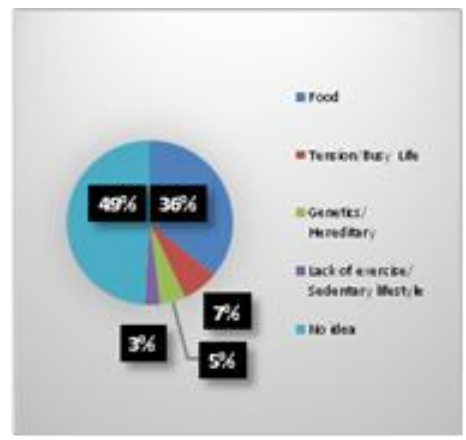

Figure 2: Knowledge about the cause of Diabetes

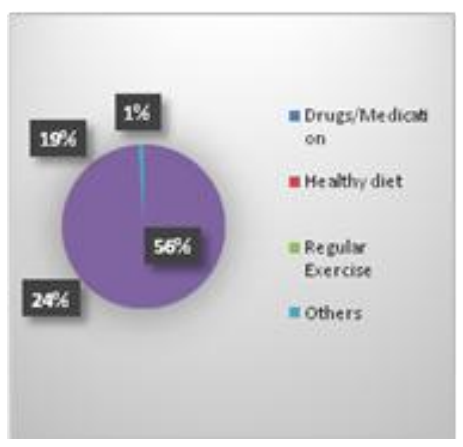

Figure 4: Knowledge about the measures to control Diabetes

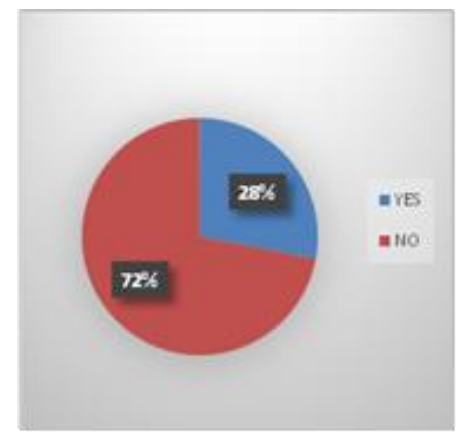

Figure B: HEto ry of hos pitaliuation for Debbetes

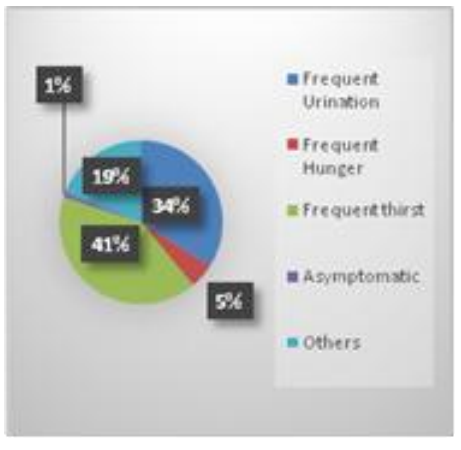

Figure 1: Knowledge about the symptoms of Diabetes

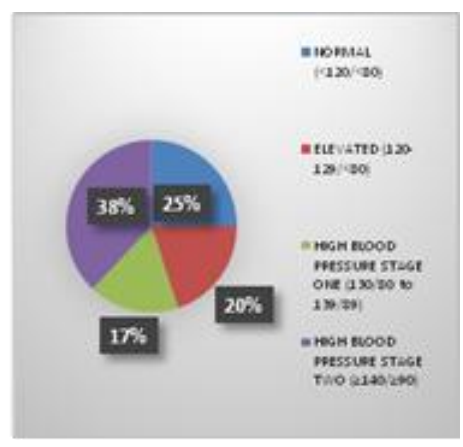

Figure 3: Blood pressure of the patients

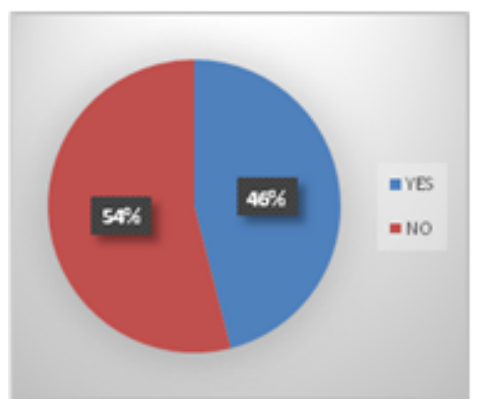

Figure 9: Include exerise in the routine 
Int.J.Curr.Microbiol.App.Sci (2018) 7(9): 1756-1763

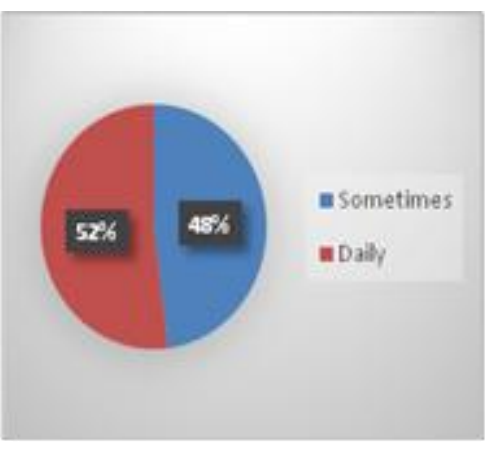

Figure 10: Frequency of e werise

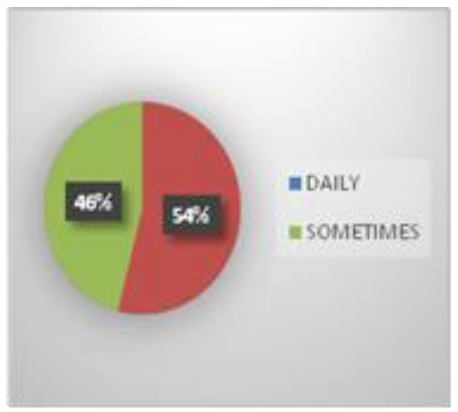

Figure 13 : Frequency of $s$ motirg

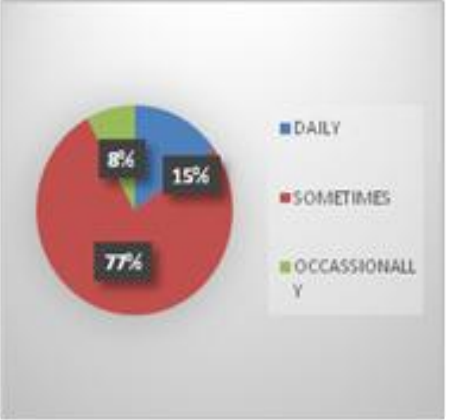

Figure 16: Frequency of core umption of akohol

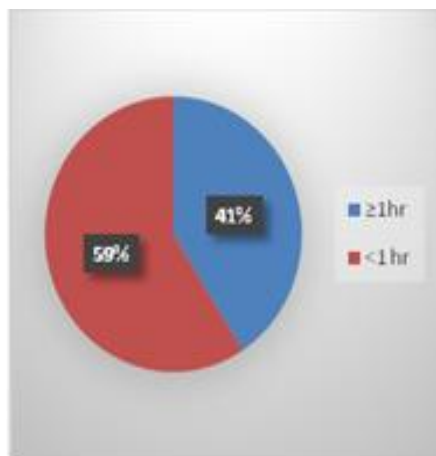

Figure 11: Duration of e wertie

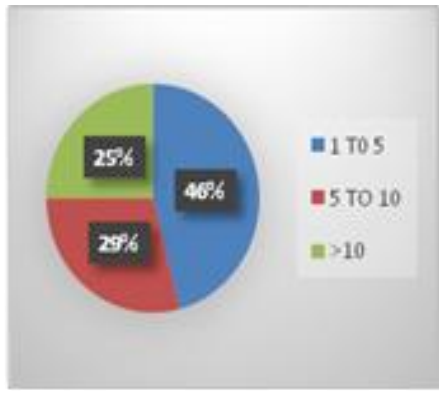

Figure 14: Number of cigrettes s moked

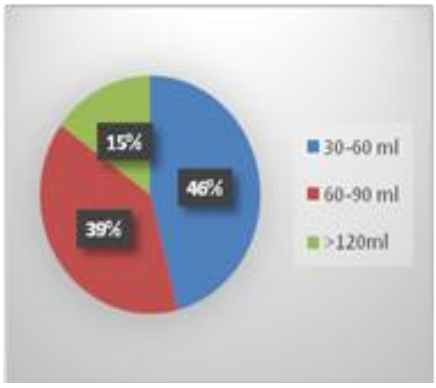

Figure 17:Amourt of akohol cors umed

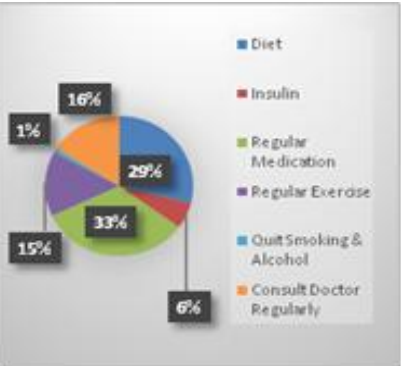

Figure 12: Diet changes adopted

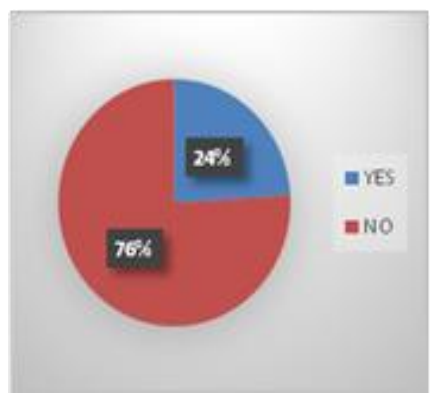

Figure 12: Presence of s moking buit

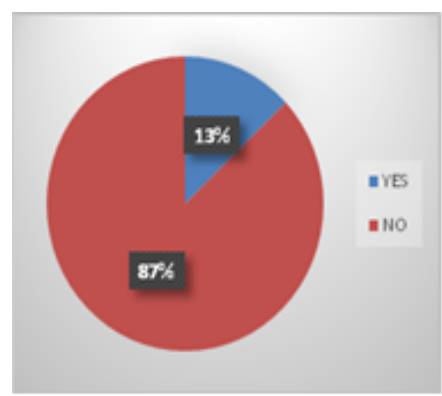

Figure 15: Consume alchohol

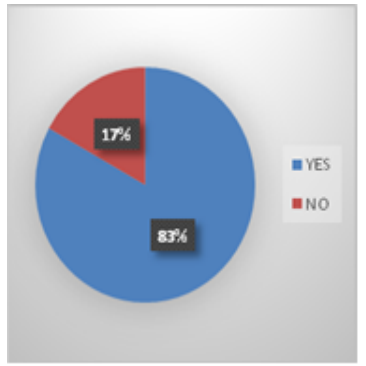

Figure 11: Control measures adopted by the patients 
Majority (46\%) consumed thirty to sixty $\mathrm{ml}$ of alcohol while $15 \%$ consumed an amount more than one hundred twenty ml (Fig. 17). A study conducted by Wei et al., (2000) found an elevated risk of developing type II diabetes in non-drinkers and men with high alcohol intake. According to the Dietary Guidelines for Americans, moderate alcohol consumption is defined as having up to 1 drink per day for women and up to 2 drinks per day for men. One standard drink equals $14 \mathrm{~g}$.

For controlling diabetes, majority of the patients (36\%) used regular medication while $1 \%$ quit alcohol as a measure to control diabetes (Fig. 18).

$83 \%$ of the patients made changes in their diet, while the remaining $17 \%$ made no changes in their diet (Fig. 19). The $83 \%$ of the patients who made changes in their diet avoided/limited food items like sweets/sugar, tea, rice, meat especially red meat, roots and tubers, pumpkin, oily and fatty foods, eggs especially the yolk, alcohol, fruits like banana and cruciferous vegetables like cabbage.

Apart from this, they consumed bitter foods like fenugreek seeds, bitter gourd, garlic, whole grains, and parboiled rice so as to control their glucose level.

The prevalence of Diabetes Mellitus among the outpatients in the Tura Civil Hospital was enormously high. It is alarming to know that even in a small town like Tura, the cases of diabetes is high. Moreover, there are still many unaccounted cases of Diabetes in the region. Incidence was higher in the urban area than in the rural area, with higher number of patients in the age group of fifty to sixty suffering from the disorder. More males than females suffered from the disease in the study population with people who lived a sedentary lifestyle and consumed non vegetarian food items being highly associated with the disease. The knowledge of the patients about the disease was also poor.
Thus, preventive measures and awareness regarding Diabetes Mellitus is needed. Furthermore, promotion of healthy lifestyle, diet and exercise should be encouraged to the people.

\section{Acknowledgement}

We are highly indebted to Dr. Minakshi A Sangma, Superintendent, Tura Civil Hospital for her cooperation, support and for allowing us to conduct the research in the hospital and Dr. Cynthia R. Marak, Diabetologist, Tura Civil Hospital, for her kind support, cooperation and suggestion throughout the entire two months in the hospital.

\section{References}

Aung, W.P., Htet, A.S., Bjertness, E., Stigum, H., Chongsuvivatwong, $\mathrm{V}$ and Kjollesdal, M.K.R. 2018. Urban -rural differences in the prevalence of diabetes mellitus among 25-74 year-old adults of the Yangon Region, Myanmar: two cross-sectional studies. British Medical Journal Open, 8(3):e020406, doi: 10.1136/bmjopen2017-020406. p. 1.

Diabetes in Urban India. CADI Research Foundation. Retrieved from http://www.cadiresearch.org/topic/diabete s-indians/diabetes-urban-india.

Diabetes is on the rise in India. Here's why you shouldn't take blood sugar lightly. 2017, Nov 23. Hindustan Times, Retrieved from https://www.hindustantimes.com/fitness/d iabetes-is-on-the-rise-in-india-here-s-why -you-shouldn-t-take-blood-sugarlightly/ story7082wb3ZEwbkXq9Bd8L.

Erber, E., Hopping, B.N. and Grandinetti, A. 2010. Dietary Patterns and Risk for Diabetes. Diabetes Care. 33(3): 532-538. doi: $10.2337 / \mathrm{dc} 09-1621$. p.532

Joseph, J.J., Tcheugui, J.B.E., Golden, S.H., Chen, H., Jenny, N.S., Carnethon, M.R., Jr, D.J., Burke, G.L., Vaidya, D., Ouyang, $P$ and Bertoni, A.G. 2016. Physical activity, sedentary behaviors and the incidence of type 2 diabetes mellitus: the 
Multi-Ethnic Study of Atherosclerosis (MESA). British Medical Journal Open Diabetes Research and Care, 4(1):e000185. doi:10.1136/ bmjrdc-2015000185.

Katayama, S., Hatano, M and Issiki, M. 2018. Clinical features and therapeutic perspectives on hypertension in diabetics. Hypertension Research, 41:213229.doi:10.1038/s41440-017-0001-5.

Malik, R. 2016, Jan 28. India is the diabetes capital of the world. The Times of India. Retrieved from https://timesofindia. indiatimes.com/life-style/health-fitness/ health-news/India-is-the-diabetes-capitalof-the-world/articleshow/50753461.cms. p. 1 .

Srilakshmi, B. 2014. Dietetics. $7^{\text {th }}$ Multicolour Edition, New Delhi: New Age International (P) Limited, Publishers. pp. 18-19.

Standard drink. Alcohol Website India. Retrieved from https://www.alcohol webindiain/content/standard-drink.

The National Committee on Prevention, Detection, Evaluation and Treatment of High Blood Pressure. 1995. $6^{\text {th }}$ Report (JNC-VI). Archive Internal Medical, 157:2413.

Thompson, P.D., Buchner, D., Pina, I.L., Balady, G.J., Williams, MA., Marcus, BH., Berra, K., Blair, SN., Costa, F., Franklin, B., et al., 2003. Exercise and physical activity in the prevention and treatment of atherosclerotic cardiovascular disease: a statement from Council on Clinical Cardiology (Subcommittee on Exercise,
Rehabilitation, and Prevention) and the Council on Nutrition, Physical Activity and Metabolism (Subcommittee on Physical Activity). Circulation, 107:3109-3116.

Tonstad, S., Stewart, K., Oda, K., Batech, M., Herring, R.P and Fraser, G.E. 2008. Vegetarian diets and incidence of diabetes in the Adventist Health Study-2. Nutrition Metabolism in Cardiovascular Diseases, 23(4): 292-299. doi:1016/j.numeed.2011. 07.004. p.292.

WHO. 2016. Global report on Diabetes. France. Retrieved from http://apps.who.int/iris/ bitstream/handle/10665/204871/9789241 565257_eng.pdf?sequence=.p. 6 .

WHO. Global Database on Body Mass Index. Retrieved from http://apps.who.int/bmi/ index.jsp?introPage=intro_3.html. Table 1.

Wiwanitkit, V. 2007. A note from a study on the prevalence of Diabetes Mellitus in a sample of vegetarians. Diabetologia Croatica, 36-1. p. 11.

Yang, W., Lu, J., Weng, J., Jia, W., Ji, L., Xiao, J., Shan, Z., Liu, J., Tian, H., Ji, Q., et al., 2010. Prevalence of Diabetes among Men and Women in China. The New England Journal of Medicine, 362:1090-101. p. 1090.

Zaman, G.S., Zaman, F.A. and Arifullah, M. 2010. Comparative risk of type 2 diabetes mellitus among vegetarians and nonvegetarians. Indian Journal of Community Medicine, 35(3):441-442. doi:10.4103/ 0970-0218.69285.p.441.

\section{How to cite this article:}

Natasha Marak, D. Alina, Ch. Momin and Leebeliya Sharma, G. 2018. Incidence and Knowledge of Diabetes Mellitus of the Residents of Tura Town: A Case Study. Int.J.Curr.Microbiol.App.Sci. 7(09): 1756-1763. doi: https://doi.org/10.20546/ijcmas.2018.709.212 